\title{
(Y)ears of Freedom? Customized Splints in Microtia Reconstruction to Maintain Cephloauricular Angle
}

\author{
S. Sridevi Shanmugam ${ }^{1}$ Janhavi Venkataraman ${ }^{1, \odot}$ \\ ${ }^{1}$ Department of Plastic, Reconstructive, and Oro-Faciomaxillary \\ Surgery, Rajiv Gandhi Government General Hospital, Madras \\ Medical College, Chennai, Tamil Nadu
}

\begin{abstract}
Address for correspondence Janhavi Venkataraman, MBBS, MS, MCh (Plastic Surgery), Department of Plastic, Reconstructive, and Oro-Faciomaxillary Surgery, Rajiv Gandhi Government General Hospital, Madras Medical College, Poonamallee High Rd, Park Town, Chennai, Tamil Nadu, (e-mail: janhavivraman@gmail.com).
\end{abstract}

\begin{abstract}
Keywords

- cephaloauricular

sulcus

- ear projection

- microtia

- customized splints

Background Maintaining ear projection and preservation of cephaloauricular sulcus from obliteration following graft contracture is a challenge following staged microtia reconstruction. Authors have designed simple, effective, and easy-to-use splints to ensure improved aesthetic outcomes and patient compliance.

Materials and Methods This is a prospective study over 3 years including 8 patients of both sexes aged 6 to 12 years. Custom-made ear splints were designed separately for females and males and used to maintain ear projection. Projection of the ear was measured postoperatively and at follow-up using goniometer and photographic records. Outcome was assessed in terms of cephaloauricular angle, conchal depth, pain, cost-effectiveness, splint retention period, and aesthetics.

Results and Conclusion Maximal follow-up was 2 years. The splint effectively maintained ear projection of more than 30 degrees. Patient compliance was optimal, and no major complications were associated with its prolonged use.
\end{abstract}

\section{Introduction}

Maintaining ear projection is essential after second-stage microtia reconstruction. ${ }^{1}$ Preservation of cephaloauricular sulcus from obliteration following graft contracture is a challenge. ${ }^{2}$ An effective splint should maintain the necessary auricular projection. Essentially, it should be self-retaining over a period of time. Various splints used have limited application owing to issues with compliance, cost-effectiveness, and the necessity to replace daily under supervision. Some are bulk and cumbersome, making it reasonably difficult to be retained in place and socially embarrassing for children. The authors have designed simple, effective, and easy-to-use splints using conventional moulds in a more feasible manner to improve aesthetic outcomes and patient compliance.

\begin{abstract}
Aim
Our aim is to evaluate the efficacy of our customized splints in defining cephaloauricular angle and maintaining ear projection.
\end{abstract}

\section{Materials and Methods}

This prospective clinical study was conducted over a period of 3 years and included six patients of both sexes aged 6 to 12 years. Outcomes were analyzed following Brent's stage II reconstruction for lobular type of microtia. Custom-made ear splints were designed separately for females and males. Splints were prepared using conventional dental moulds in order to snugly fit in the retroauricular space. Splints were anchored using various innovative means as per individual needs. Designs included spectacles, anchorage splints, thin hair bands camouflaged in the hair in males, and fancy-looking hair bands in females. Prior consent for the splint application was obtained by the patients/parents. For females who desired to wear earrings, a new splint was designed in the form of chain (mattal in Tamil) and ear stud (jhumkis in Hindi). The mould was incorporated on the posterior aspect of the chain, which was concealed by hair. These moulds were also painted in skin tone fabric colors for better aesthetic results. Ear piercing was performed under aseptic published online September 10, 2019
DOI https://doi.org/

$10.1055 / \mathrm{s}-0039-1693848$ ISSN 0970-0358.
C2019 Association of Plastic Surgeons of India
License terms

(요 (1) $\Theta \circledast$ 
precautions. These splints were designed very similar to the traditional earrings worn by the local population.

\section{Procedure}

A dental mould was placed in hot water for few minutes till it softened. It was then taken out and cooled. A softened mold was fashioned in a desired wedge (C) shape to snugly fit the created retroauricular space. The mould was wrapped around over a solid framework of thin stainless steel wire attached to

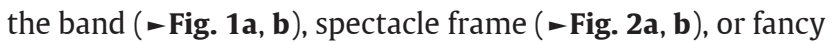

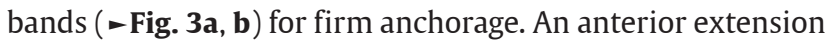
of the splint was given in superior aspect for a better hold. No other tape or bandage was used. In case of the earring-type splint ( $\mathbf{- F i g .} \mathbf{4 a}, \mathbf{b}$ ), it was incorporated on the posterior link chain (mattal) of the jewelry.

The splint was placed at the back of the elevated ear framework (cephaloauricular sulcus) after applying an antibiotic cream over the grafted skin ( - Fig. 5). The splint was applied 1 week after surgery once the graft had taken well. The patient was asked to use the splint constantly except during bathing.

Ear projection was measured postoperatively and at follow-up using a goniometer documentation using photography. Patients were reviewed at 1 month after surgery and every 2 months for 1 year thereafter. Splint was continued for 6 to 8 months postsurgery. Outcome was assessed in terms of cephaloauricular angle, conchal depth, pain, cost-effectiveness, splint retention period, and aesthetics as perceived by two independent observers. A scoring scale (1-5) was used. Statistical analysis was performed using the Student $t$-test, and $p<0.05$ was considered to be statistically significant.

\section{Results}

- The study included five females and three males.

- The splint effectively maintained ear projection (average $30 \mathrm{~mm}$ ).

- Average splint retention period was 5.8 months.

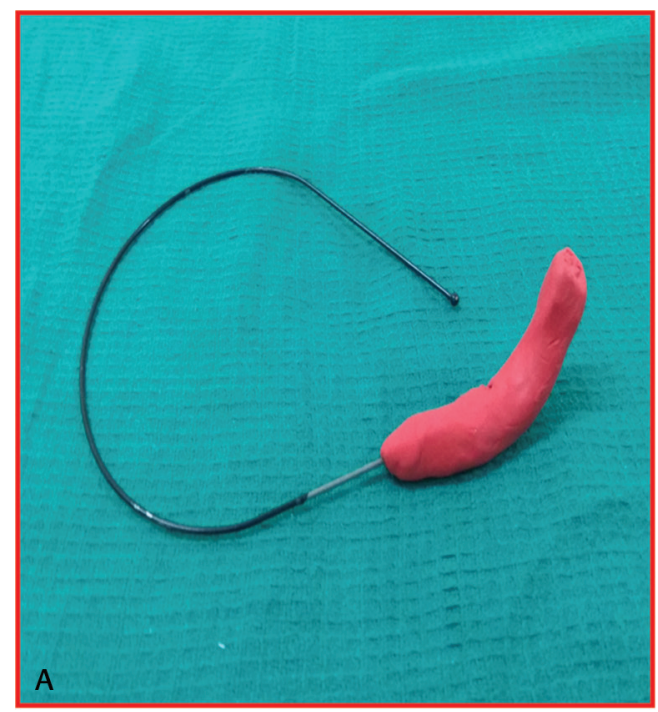

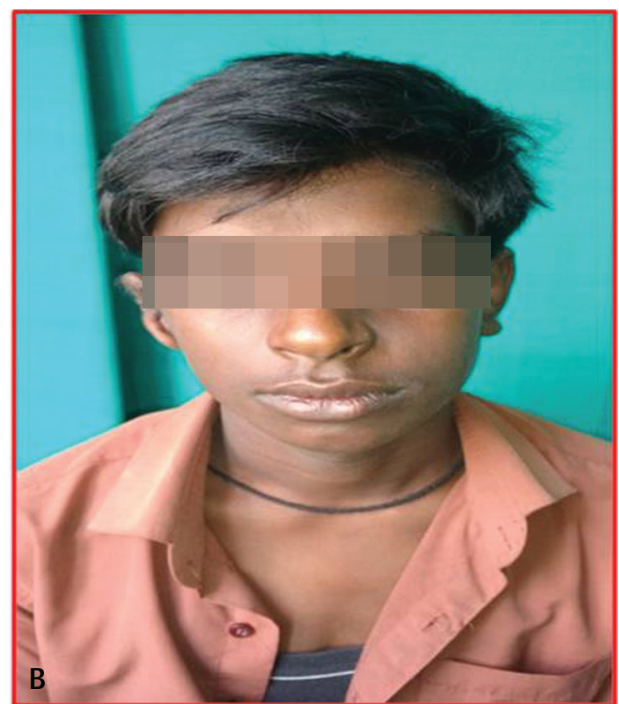

Fig. 1 (a) Splint with thin wire band framework. (b) Splint with thin wire band application.
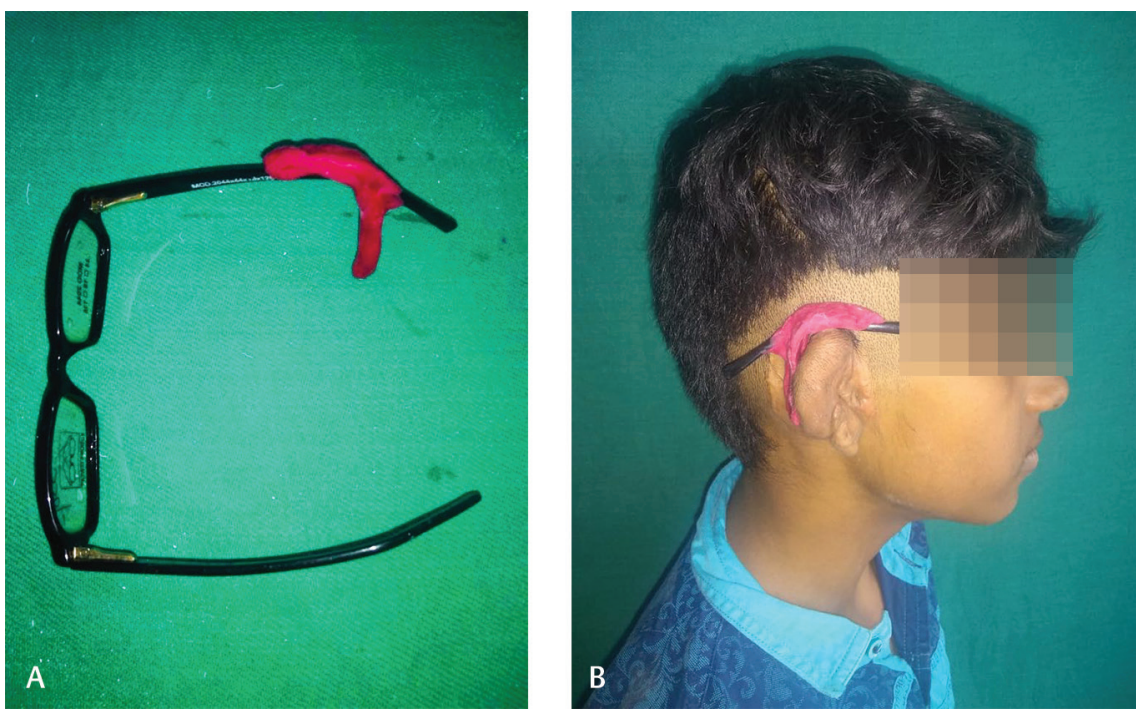

Fig. 2 (a) Splint with spectacle framework. (b) Splint with spectacle framework application. 


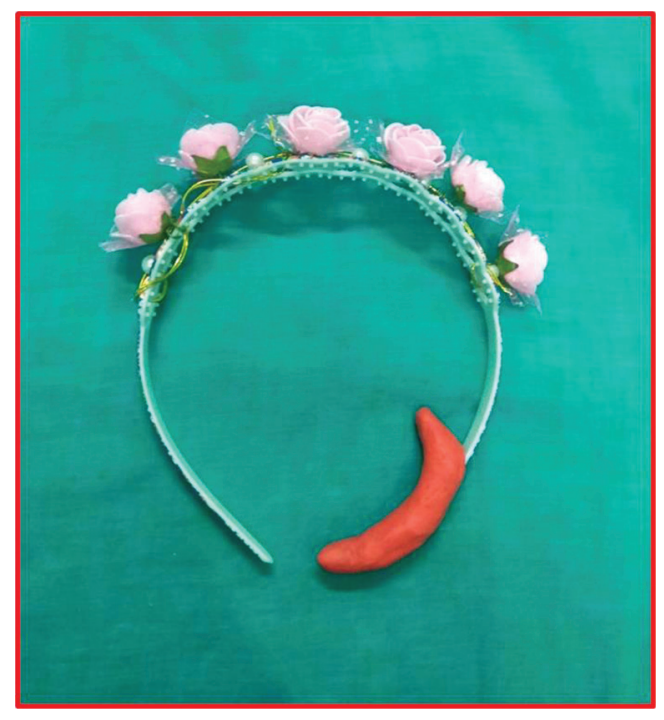

Fig. 3 Splint with fancy hair band framework.
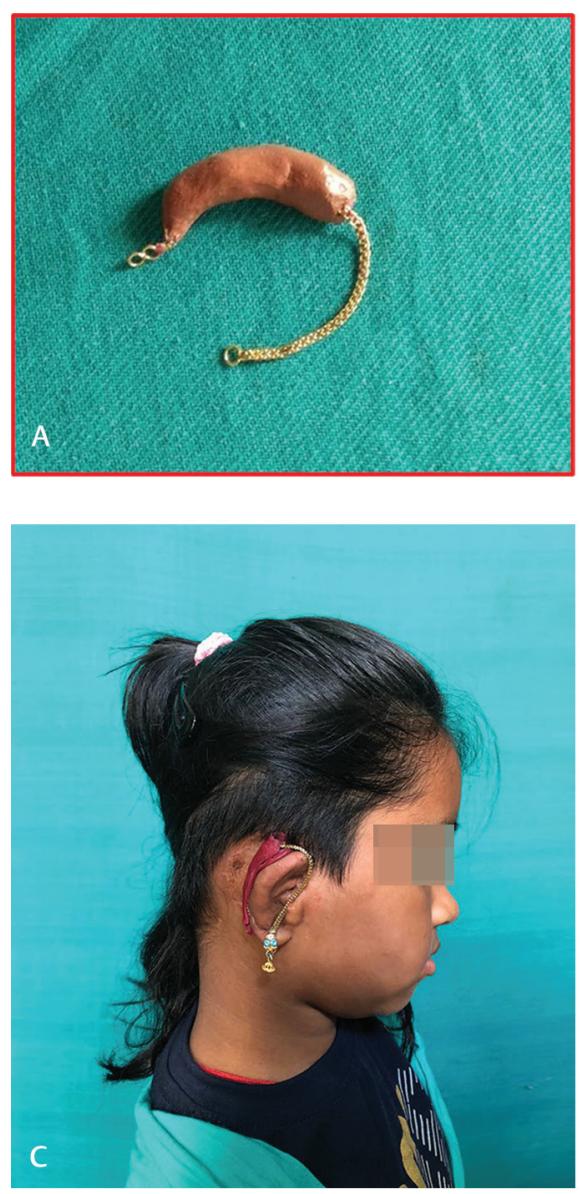

Fig. 4 (a-d) Splint with mattal earring framework application.

- Patient compliance was optimal, and no major complications were associated with its use.

- Patient aesthetics and satisfactory score was 97 to $98 \%$.

- There was no skin graft loss or infection in any of the cases.

- There was no pain experienced by the patients during the splint application till removal.
- Patients were highly satisfied with the splint designs as it was aesthetically appealing and well suited to their need of using earrings like a normal child ( - Table $\mathbf{1}$ ).

\section{Discussion}

Numerous splints have been described for maintaining the retroauricular space after ear framework elevation in microtia surgery. ${ }^{2}$ These range from simple conventional dental moulds, ${ }^{1}$ acrylic based resins, ${ }^{2}$ silicon Foleys catheter, ${ }^{3}$ and thermoplastic materials, to dressing techniques ${ }^{4}$ and spectacle frames. ${ }^{5}$ These have limited application owing to scarce availability, difficult compliance, cost, and the necessity to replace daily under supervision. Some are bulk and cumbersome, making it difficult to retain in place and socially embarrassing for children. The literature has limited reports of splints used for the maintenance of the desired position of the elevated ear., ${ }^{3,6}$
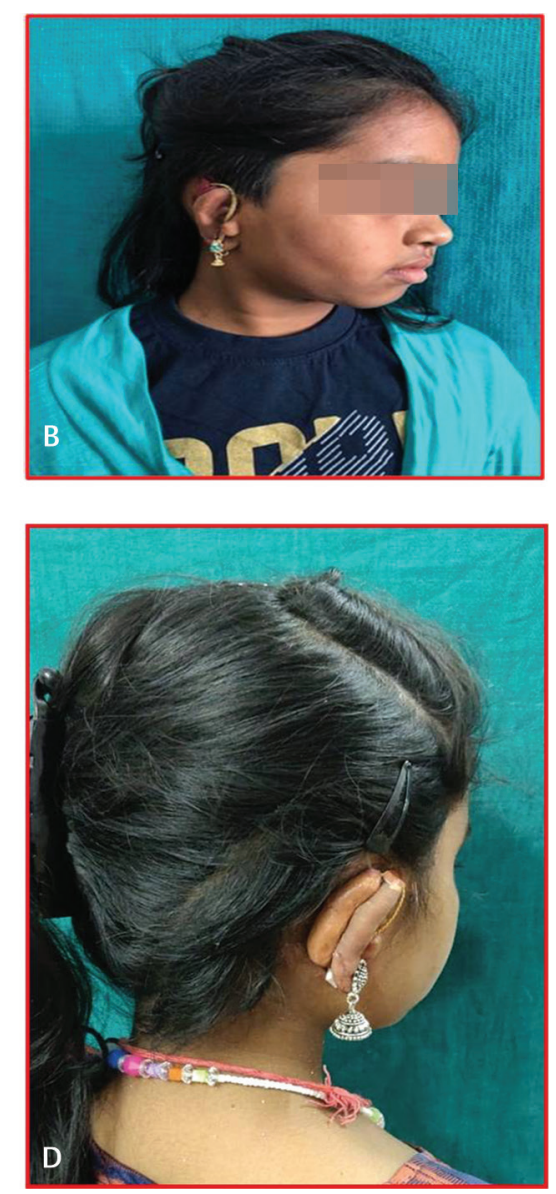

Nagata's technique uses cartilage block for ear elevation and a temporoparietal fascial flap cover. ${ }^{7}$ Other techniques include expanded retroauricular skin and fascial flap, ${ }^{8}$ retroauricular fascial flap and wrapping of the wedge of autogenous costal cartilage, ${ }^{9}$ and modifications. ${ }^{10}$ Inspite of these, the ear projection is lost due to secondary graft contracture. 

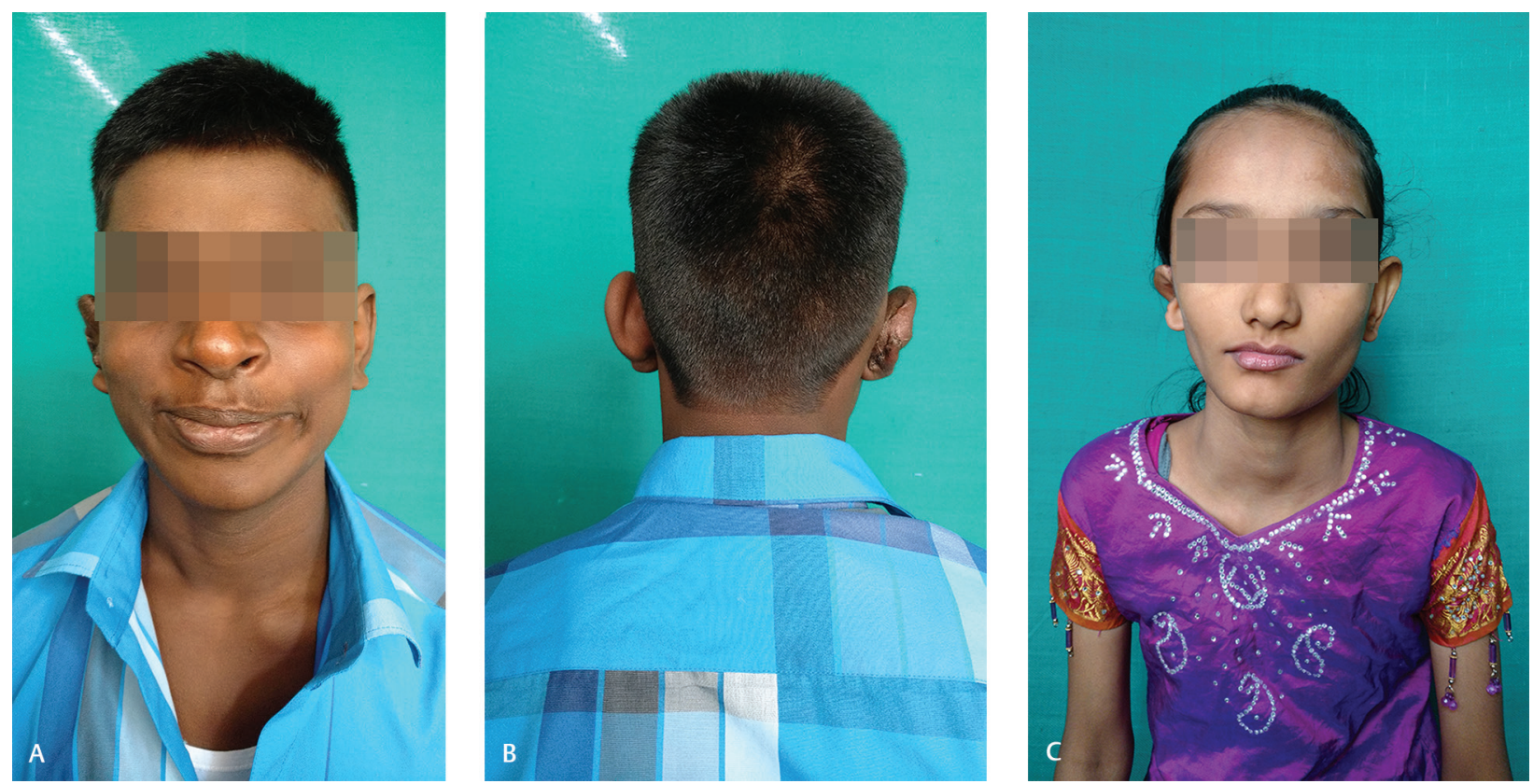

Fig. 5 (a-c) Postsplint application ear projection.

Table 1 Table showing details of the splint applied and post application results (variables) in patients.

\begin{tabular}{|c|c|c|c|c|c|c|c|c|}
\hline S. no & Age / sex & $\begin{array}{l}\text { Splint } \\
\text { type }\end{array}$ & $\begin{array}{l}\text { Cephaloauricular } \\
\text { angle at } 1 \text { mo } \\
\text { postoperative }\end{array}$ & $\begin{array}{l}3 \text { mo } \\
\text { postoperative } \\
\text { (degrees) }\end{array}$ & $\begin{array}{l}6 \text { mo } \\
\text { postoperative } \\
\text { (degrees) }\end{array}$ & $\begin{array}{l}\text { Ear } \\
\text { projection } \\
(\mathrm{mm})\end{array}$ & Pain & $\begin{array}{l}\text { Splint } \\
\text { retention } \\
\text { period } \\
\text { (months) }\end{array}$ \\
\hline 1 & $10 / F$ & Specs & 40 & 30 & 30 & 30 & Nil & 8 \\
\hline 2 & $7 / F$ & Earring & 55 & 50 & 40 & 18 & $\begin{array}{l}\text { Minimum } \\
\text { discomfort } \\
\text { for a week }\end{array}$ & 6 \\
\hline 3 & $6 / \mathrm{M}$ & $\begin{array}{l}\text { Hair } \\
\text { band }\end{array}$ & 45 & 40 & 40 & 22 & - & 5 \\
\hline 4 & $7 / F$ & Earring & 50 & 45 & 35 & 20 & - & 6 \\
\hline 5 & $6 / \mathrm{M}$ & Specs & 50 & 45 & 40 & 28 & - & 6 \\
\hline 6 & $7 / F$ & Earring & 45 & 40 & 35 & 24 & - & 5 \\
\hline 7 & $6 / \mathrm{M}$ & $\begin{array}{l}\text { Hair } \\
\text { band }\end{array}$ & 45 & 35 & 35 & 28 & - & 6 \\
\hline 8 & $8 / F$ & Earring & 45 & 40 & 40 & 30 & - & 5 \\
\hline
\end{tabular}

Abbreviations: $F$, female; $M$, male.

The authors have designed simple, effective, and easy-touse splints using conventional moulds to facilitate better aesthetic outcomes and patient compliance. These customized splints have proved to be superior in terms of projection and patient satisfaction. Though dental moulds have been routinely used in various studies for the same purpose, firm longterm anchorage of the mould in the retroauricular space was not accomplished, which led to frequent falling and breakage of the splint. ${ }^{1}$ This problem was not seen with these customized splints. Silicon foley catheter splints could be used only in patients with intact external auditory meatus. ${ }^{3}$ Besides, these are easily visible and may be less aesthetically acceptable. Nevertheless, these are good for maintaining meatal patency in case of stenosis.
Dressing techniques used for splintage require frequent dressing changes and are cumbersome. These are not suitable for long-term use. ${ }^{4}$

Though ethylene-vinyl acetate custom-made ear splint can be used for long term with good results, these are still not completely camouflaged and seen as transparent splints and can fall off. ${ }^{11}$

2-Octyl-cyanoacrylate skin adhesive has been used as an auricular splint ${ }^{12}$ after prominent ear surgery, but its use after microtia reconstruction is not described yet.

The splints described by authors (1) are aesthetically acceptable and are incorporated in readily used hair and ear accessories, (2) are painted to get a close match to patients" skin tone, (3) are easily camouflaged by hair, (4) are 
cost-effective as readily available materials are used to make the splint, (5) are non alleregenic, (6) reduce number of postoperative visits, and (7) give excellent patient satisfaction as they give the perception of a naturally worn earring.

\section{Conclusion}

These customized splints are self-retaining, easy to fabricate, concealable, inexpensive, lightweight and maintain the required auricular projection and definition. They also satisfy the patient's need for psychological and social acceptability. These splints have excellent patient compliance and help in minimizing adhesions. We anticipate that this simple innovative technique would provide a prospective solution to some of the difficulties that may arise with otoplastic reconstruction.

\section{Conflict of Interest}

None.

\section{References}

1 Bhandari PS, Singh S. Dental impression compound as an effective splint for maintenance of ear elevation in microtia reconstruction. Indian J Plast Surg 2013;46(3):518-520

2 Krishnan CJ, Balaji SM, Jain AR. A simple ear splint for microtia patients. Indian J Dent Res 2015;26(2):220-221

3 Karanth SK, Mokal NJ. Silicone Foley's catheter: a useful splint in ear surgeries. Indian J Plast Surg 2008;41(1):51-54
4 Puri V, Kare N, Venkateshwaran N. A simple method of applying ear dressing in microtia patients. Indian $\mathrm{J}$ Otol 2012;18:154-155

5 Balaji SM. Two stage ear/microtia reconstruction using costal cartilage. Ann Maxillofac Surg 2015;5(2):163-167

6 Yotsuyanagi T, Yokoi K, Urushidate S, Sawada Y. A supportive technique using a splint to obtain definite contour and desirable protrusion after reconstruction of microtia. Plast Reconstr Surg 1998;101(4):1051-1055

7 Nagata S. Modification of the stages in total reconstruction of the auricle: part IV. Ear elevation for the constructed auricle. Plast Reconstr Surg 1994;93(2):254-266

8 Zhang Q, Quan Y, Su Y, Shi L, Xie Y, Liu X. Expanded retroauricular skin and fascial flap in congenital microtia reconstruction. Ann Plast Surg 2010;64(4):428-434

9 Ou LF, Yan RS, Tang YW. Firm elevation of the auricle in reconstruction of microtia with a retroauricular fascial flap wrapping an autogenous cartilage wedge. $\mathrm{Br} \mathrm{J}$ Plast Surg 2001;54(7):573-580

10 Prantl L, Ashary I, Eisenmann-Klein M, Schwarze H. Modification of the second stage of auricular elevation in Nagata's technique for treating microtia. Scand J Plast Reconstr Surg Hand Surg 2007;41(3):109-113

11 Vercruysse H, Jr. Green JI, Osman G, Harrison B, Miyagi K, Bulstrode NW. Splinting after ear reconstruction: a stepwise and inexpensive workflow protocol. Ann Plast Surg 2018;80(4):356-358

12 Yamamoto N, et al. 2-Octyl-cyanoacrylate skin adhesive used as a splinting material in auricular surgery. Modern Plastic Surgery 2016;6:21-26 